Earth Syst. Dynam. Discuss., doi:10.5194/esd-2017-13, 2017

Manuscript under review for journal Earth Syst. Dynam.

Discussion started: 22 February 2017

(c) Author(s) 2017. CC-BY 3.0 License.

\title{
Past and future influence of climate change on spatially heterogeneous vegetation activity in China
}

Jiangbo Gao ${ }^{1, *}$, Kewei Jiao ${ }^{1,2, *}$, Shaohong $\mathrm{Wu}^{1}$, Danyang $\mathrm{Ma}^{1,2}$, Dongsheng Zhao ${ }^{1}$, Yunhe Yin ${ }^{1}$, and Erfu Dai ${ }^{1}$

$5{ }^{1}$ Key Laboratory of Land Surface Pattern and Simulation, Institute of Geographic Sciences and Natural Resources Research, Chinese Academy of Sciences, Beijing 100101, China,

${ }^{2}$ University of Chinese Academy of Sciences, Beijing 100049, China

*These authors contributed equally to this work.

Correspondence to: Jiangbo Gao (gaojiangbo@igsnrr.ac.cn)

10 Abstract. Climate change is a major driver of vegetation activity, and thus their complex relationships become a frontier and difficulty in global change research. In this paper, the spatial distribution and dynamic variation of climate change impacts on vegetation activity from 1980s to 2050 in China were investigated by the Geographically Weighted Regression (GWR) model, based on the combined datasets of satellite vegetation index, climate observation and projection, and future vegetation productivity simulation. Our results noted that the significant positive precipitation-vegetation relationship was

15 and will be almost distributed in the north of China, except the northeast and northwest China with significant but varying influence of temperature rising, while the regions with temperature dominated vegetation activity mainly located in the southern part of China. There will be different climatic dominators for vegetation activity in some regions such as northwest China, and even opposite correlation in the northeast China, and further the responding patterns of vegetation activity to precipitation variation will be moving southward in the future three decades. It is indicated that although high warming rate will restrain the vegetation activity, precipitation variability can mediate the hydrothermal conditions for vegetation activity, for example the enhanced vegetation activity in the Tibetan Plateau and the weakened vegetation activity in the East and Middle China in the future. Furthermore, coupling the responding patterns and the dynamic variation, it can be found that during the period from 2021 to 2050, vegetation in most of north China may adapt to an arid environment, while in many southern parts it will be repressed due to water shortage. However, the continuous and dynamic responding process of vegetation activity to climate change will be determined by the spatial heterogeneity in climate change and vegetation cover.

\section{Introduction}

Vegetation is the primary producer of terrestrial ecosystems, and also plays a significant role in the energy transfer between land and atmosphere and the climate regulation (Wang et al., 2012). Many features, such as vegetation growth, coverage, phenology and carbon cycle process, can mirror the vegetation activity at large scales (Fang et al., 2004). As the necessary environmental variables, climate change has and will have profound influences on the spatially heterogeneous vegetation 
Earth Syst. Dynam. Discuss., doi:10.5194/esd-2017-13, 2017

Manuscript under review for journal Earth Syst. Dynam.

Discussion started: 22 February 2017

(c) Author(s) 2017. CC-BY 3.0 License.

activity (Zhao and Running, 2011; Dong and Sutton, 2015). Investigation on the vegetation response to climate change and its spatial variation can provide theoretical basis for ecosystem-based adaptation, and thus becomes a major topic of global change research.

Studies on the relationships between vegetation activity and climate change have been carried out at different spatial 5 scales (Krishnaswamy et al., 2014; Seddon et al., 2016). However, the specific variation in vegetation activity depends on different environmental conditions and their changes. Del Grosso et al. (2008) found that $13 \%$ increase in total global Net Primary Productivity (NPP) for potential vegetation over the last century due to a significantly positive correlation between NPP and climatic factors. As for the regional scales, a continuously rising trend of NPP at a rate of $0.22 \% / a$ was noted in the tropical and subtropical zones, while a continuously decreasing trend $(-0.05 \% / \mathrm{a})$ appeared in the temperate zone in China

10 (Wang et al., 2008). Additionally, because of the spatial heterogeneity in vegetation cover, together with the strong regional differences in precipitation (de Jong et al., 2013; Zeppel et al., 2014; Duo et al., 2016), the increased precipitation concentration caused the decreased NPP in semiarid regions (Fay et al., 2008; Hoover et al., 2014), but increased NPP in arid regions (Baez et al., 2013).

Most former research applied correlation and trend analysis to detect vegetation effects of climate change, but studies

15 on the dynamic response of vegetation activity to climate variability and the influencing mechanism were still relatively weak (Reyer et al., 2013). Actually, the relationship between climate and vegetation may vary with time scales, including years, seasons, and even day and night (Piao et al., 2008, 2014; Peng et al., 2013). For example, Wang et al. (2016) found a large percentage increase of NPP in northwest China and Tibetan Plateau over the 21st century under the four emission scenarios, which was different from the decrease trend over the past. Thus, due to the crossing effects of spatial and temporal

20 scales, the vegetation-climate correlations present the characteristics of complexity and uncertainty.

Generally, previous studies on climate-vegetation relationships in China were still concerned with historical periods and local features (Wang et al., 2005; Baez et al., 2013). Transfers of responding patterns from past to future at national scale need to attract more attention, or it is not conducive to the development of targeted, orderly adaptation strategy. Therefore, in this paper, the geographically weighted regression (GWR) and other statistic methods were used to investigate the response 25 patterns of vegetation activity to climatic change and their variability from 1980s to 2050 in China, in order to identify the effective factors and regions during different periods. And further, through the dynamic description of climate induced vegetation activity from rise to decline in different regions, it is expected to provide scientific basis for making ecosystembased adaptation strategies in response to global climate change. 
Earth Syst. Dynam. Discuss., doi:10.5194/esd-2017-13, 2017

Manuscript under review for journal Earth Syst. Dynam.

Discussion started: 22 February 2017

(c) Author(s) 2017. CC-BY 3.0 License.

\section{Materials and methods}

\subsection{Data}

\subsubsection{Vegetation activity}

Two vegetation indicators, including Normalized Difference Vegetation Index (NDVI) and Net Primary Productivity (NPP),

5 were applied to present vegetation activity (Robertson et al., 2009; Wright et al., 2012). The satellite-based NDVI is independent from the climate observations, so they are appropriate for correlation fitting. As for the future scenario, the projected NPP simulated by ecological model was applied to analyze the climate-vegetation relationships.

NDVI dataset from 1982 to 2013 at a spatial resolution of $8 \mathrm{~km}$ and temporal interval of 15-day were obtained from the GIMMS (Global Inventory Modeling and Mapping Studies) group, and then the original NDVI dataset was resampled to

$10 \quad 0.5^{\circ}$ spatial resolution by ArcGIS 10.3 to match climate dataset. This dataset is known as its high quality and the longest time series, and has been widely used in many studies of global and regional vegetation activity (Tucker et al., 2005; Mao et al., 2012).

Projected NPP from 2021 to 2050 at a spatial resolution of $0.5^{\circ}$ were simulated by LPJ-DGVM (Lund-Potsdam-Jena Dynamic Global Vegetation Model). Climate data imported to the model was divided into two parts: one was derived from

15 the historical simulation data (1981-2010) published by the National Climate Center of CMA (China Meteorological Administration) in order to validate the climate simulation results, and the other was climate scenario data from 2021 to 2050 under RCP4.5, a stabilization emission scenario that assumed the imposition of emissions mitigation policies. And the soil texture data imported was derived from FAO (Food and Agriculture Organization of the United Nations), with a $1^{\circ}$ spatial resolution. The detailed information was described in the following parts.

\section{$20 \quad$ 2.1.2 Climatic variables}

In the past analysis, raster data of $0.5^{\circ}$ spatial resolution, which were interpolated from 2472 meteorological stations nationwide through thin plate spline (TPS) combining with 3D geospatial information by the National Climate Center of CMA, was applied to represent climate change, including annual temperature and precipitation from 1982 to 2013. In the future analysis, monthly climatic data including temperature and precipitation from 2021 to 2050 were provided by the

25 National Climate Center of CMA. They simulated these data of China under RCP4.5 emission scenario by regional climate mode (RegCM4.0) from the Abdus Salam International Centre for Theoretical Physics (ICTP), and interpolated them into $0.5^{\circ}$ spatial resolution. 
Earth Syst. Dynam. Discuss., doi:10.5194/esd-2017-13, 2017

Manuscript under review for journal Earth Syst. Dynam.

Discussion started: 22 February 2017

(c) Author(s) 2017. CC-BY 3.0 License.

\subsection{Methods}

\subsubsection{Lund-Potsdam-Jena Dynamic Global Vegetation Model (LPJ-DGVM)}

The LPJ-DGVM has been widely applied to study the vegetation dynamics including the processes of establishment, mortality and disturbance by wildfires (Sitch et al., 2003). The input data for LPJ-DGVM included the climate data (i.e. monthly temperature, precipitation and cloud cover), soil texture data, and atmospheric $\mathrm{CO}_{2}$ concentration. Based on the photosynthesis, canopy energy balance, distribution of photosynthates in plants and soil water balance, the model could simulate the stomatal conductance, photosynthesis, respiration, foliage and leaf litter, resource competition, tissue turnover, soil microbial decomposition process, and then calculate the carbon cycle, $\mathrm{CO}_{2}$ and moisture flux, photosynthetic rate, primary productivity and carbon storage of vegetation. Moreover, variation of plant functional types (PFTs) was taken into

10 account in the simulation. At first, a 1000-year model spin-up was run in order to approach equilibrium with respect to vegetation covers and carbon pools for the terrestrial ecosystem. And then, LPJ-DGVM was driven by climate data (Sect. 2.1.1) to execute a simulation for projected NPP. For better simulation in China, LPJ-DGVM was carefully improved by adding shrub and cold grass PFTs, which were parameterized based on various inventory and observational data in accordance with the characteristics of ecosystems in China (Zhao et al., 2013). The simulated NPP by the modified model

15 was validated with the data of observed sites in China, where the correlation coefficient $\left(R^{2}=0.64, p<0.01\right)$ was better than the original LPJ-DGVM data $\left(\mathrm{R}^{2}=0.10\right)$ used by $\mathrm{Ni}(2003)$.

The historical simulation from 2000 to 2010 reflected the spatial distribution of NPP downtrend from southeast to northwest in China, which is in agreement with the MODIS NPP datasets (Liu et al., 2013). Higher NPP was distributed in south China and the maximum was approximately in the Yunnan-Guizhou Plateau, while the lower was located in the northwest arid regions and the Tibetan Plateau. In the Northeast Plain and Loess Plateau, however, the simulated NPP was higher than MODIS NPP. On one hand, both remote sensing interpretation and LPJ-DGVM simulation have a certain uncertainty. On the other hand, the LPJ-DGVM may under-estimate the negative impacts of drought in these regions.

For different PFTs, simulated NPP in this paper was compared with Chen et al. (2012), which collected NPP data (including model estimates and field measures) in China from 98 research papers. The statistical results showed that the difference between the average LPJ-DGVM simulated NPP and the observations is smaller for most PFTs, especially for needleleaved evergreen/deciduous forests and grasslands. However, the tropical broadleaved evergreen/monsoon and broadleaved evergreen forests, occupying small area of China, showed a relatively larger deviation than observations and multi-models simulated values (Table 1). The reason may be that human activities, such as ecological rehabilitation, have a great impact on NPP besides climate change.

Overall, by the verification of spatial pattern and varying ranges of simulated NPP, the LPJ-DGVM presented good performance to meet the need of our study on the spatio-temporal variations in the correlation between climate change and vegetation activity in China. 
Earth Syst. Dynam. Discuss., doi:10.5194/esd-2017-13, 2017

Manuscript under review for journal Earth Syst. Dynam.

Discussion started: 22 February 2017

(c) Author(s) 2017. CC-BY 3.0 License.

\subsubsection{Geographically weighted regression (GWR)}

GWR extends the traditional regression techniques to consider the spatial heterogeneity in climate-vegetation correlations by assigning weight values (Fotheringham et al., 2002). So the regression and its parameters in each point of space are quantified separately and independently. It was conducted to reveal the spatial variations in relationships between vegetation

5 and climatic variables. Both the spatial distribution and the dynamics patterns were considered by the GWR model. It is represented as:

$y_{i}=\beta_{0}\left(\mu_{i}, v_{i}\right)+\sum_{k=1}^{p} \beta_{k}\left(\mu_{i}, v_{i}\right) x_{i k}+\varepsilon_{i}$,

where $y_{i}$ is dependent variable, $x_{i k}$ is independent variables, $\varepsilon_{i}$ represent the random error term. $\left(\mu_{i}, v_{i}\right)$ expresses the spatial location of the sample $i . k$ denotes the independent variable number. $\beta_{0}$ is the intercept and $\beta_{k}$ is the regression parameters at

10 location $i$. In this paper, the multi-annual average climatic variables and vegetation activity were applied in GWR for getting responding patterns, and further their annual variability was used to detect dynamic response.

The regression coefficients are expressed by:

$\beta\left(\mu_{i}, v_{i}\right)=\left(X^{T} W\left(\mu_{i}, v_{i}\right) X\right)^{-1} X^{T} W\left(\mu_{i}, v_{i}\right) Y$,

where $\beta\left(\mu_{i}, v_{i}\right)$ represents the estimate of the regression coefficient. $W\left(\mu_{i}, v_{i}\right)$ is the weighting matrix, and $X$ and $Y$ are matrices for independent and dependent variables, respectively. The weighting matrix can be calculated as follows:

$\omega_{i j}=\exp \left(-\frac{d_{i j}^{2}}{b^{2}}\right)$

where $\omega_{i j}$ expresses the weight of sample $j$ for sample $i, d_{i j}$ represents the Euclidean distance between samples $i$ and $j$, and $b$ is the kernel bandwidth. Furthermore, the corrected Akaike Information Criterion (AICc) and the coefficient of determination $\left(\mathrm{R}^{2}\right)$, describing model's predictive ability, were performed to determine the appropriate bandwidth, meaning lower AICc and higher $\mathrm{R}^{2}$.

\subsubsection{Trend analysis}

The vegetation and climatic trend for each pixel was estimated by ordinary least squares (OLS) based on unitary linear regression using ArcGIS 10.3 software:

$\theta_{\text {slope }}=\frac{n \times \sum_{i=1}^{n} i \times Y_{i}-\sum_{i=1}^{n} i \sum_{i=1}^{n} Y_{i}}{n \times \sum_{i=1}^{n} i^{2}-\left(\sum_{i=1}^{n} i\right)^{2}}$,

25 where $\theta_{\text {slope }}$ is the regression slope that represents the change trend. $n$ is the sequence number of years. $Y_{i}$ refers to the climatic or vegetation variables for the specific year. 
Earth Syst. Dynam. Discuss., doi:10.5194/esd-2017-13, 2017

Manuscript under review for journal Earth Syst. Dynam.

Discussion started: 22 February 2017

(c) Author(s) 2017. CC-BY 3.0 License.

\subsubsection{Accumulative anomaly}

Accumulative anomaly analysis was used to identify the turning year in the future changes of NPP in this study. It is a commonly method to identify the changing tendency of discrete data. The equation can be expressed as follows:

$\widehat{X}_{L}=\sum_{i=1}^{n}\left(N P P_{i}-\overline{N P P}\right)$,

5 where $X_{i}$ is accumulative anomaly for the NPP in the $i$ th year. $\overline{N P P}$ is the mean value of the $N P P_{i}$, and $\mathrm{n}$ is the sequence number of years. As shown in this formula, the accumulative anomaly can be used to analyze the fluctuation magnitude of a series of NPP. If the changing curve is comprised at least two parts of the tendency, then the turning year can be found.

\section{Results}

Spatial regression method, GWR model in this study, was adopted to analyze vegetation activity in relation to climatic

10 variables for the periods of 1980s-2010s and 2021-2050. Through simulating the climate-vegetation relationship and its conversion, the transfer traits of responding patterns in the future can be identified.

\subsection{Existing climate change impacts on vegetation activity and their distribution}

\subsubsection{Climate-vegetation relationships: annual average}

The normalized annual temperature, precipitation and NDVI, after the check of collinearity, were used to calculate the

regression coefficient from GWR model. The normalized coefficients for climate-vegetation relationships were applied to reveal the relative importance of climate factors for vegetation activity in different regions of China. Combined with the analysis on vegetation and climate trends, the climatic determinants for vegetation activity can be obtained. At then, the 'effect region', which is defined as the spatial domain of climatic determinants for vegetation activity, has been illustrated in Fig. 1.

Temperature and precipitation played a promoting role on vegetation activity in most parts of China. The effect regions of positive precipitation-vegetation relationship were found in the north of China, such as southwest of the Northeast Plain and the Loess Plateau. While the positive temperature-vegetation relationship were distributed in the south of China, including the Huanghuai Plain, Qinling Mountains, Yangze Plain and the Western Sichuan Plateau to Yunnan-Guizhou Plateau.

In the Greater Khingan Mountains, Sanjiang Plain and several parts of northwest China, the mainly type of effect regions was a negative temperature-vegetation relationship, which meant the vegetation activity weakened with warming. The evapotranspiration accelerated with temperature increasing, which lead to the drought (Zhang et al., 2014). In some regions like the Tibetan Plateau, the effect of temperature and precipitation was not consistent with the varying trend of NDVI. It is indicated that other factors (terrain, radiation, etc.) have more significant effect on vegetation than temperature 30 and precipitation. 
Earth Syst. Dynam. Discuss., doi:10.5194/esd-2017-13, 2017

Manuscript under review for journal Earth Syst. Dynam.

Discussion started: 22 February 2017

(c) Author(s) 2017. CC-BY 3.0 License.

\subsubsection{Climate-vegetation relationships: annual variability}

Combined with the analysis on vegetation and climate trends (Fig. 2), the climatic determinants for vegetation dynamics can be obtained. The climate variability and the varying rate of NDVI were applied in GWR as independent and dependent variables, respectively, to conduct the spatial correlation analysis on climate change and vegetation dynamics.

The correlation between NDVI variability and temperature variability was positive in the areas of the North China, the northwest and southeast of China (Fig. 3a), where NDVI rate was increasing (Fig. 2a). Among these areas, the North China and northwestern part were located in the effect regions of positive precipitation-vegetation relationship (Fig. 1). The precipitation was increasing (Fig. 2b) and the correlation between NDVI variability and precipitation variability was positive (Fig. 3b). The southeastern part was located in the effect regions of positive temperature-vegetation relationship. However,

10 the precipitation trend and vegetation dynamic response to precipitation variability were opposite to the former. Therefore, both temperature and precipitation variability influence the vegetation activity together.

In the Loess Plateau, the East China, and the southwest and northeast of China, correlation between NDVI variability and temperature variability was negative (Fig. 3a). The Loess Plateau, where precipitation was increasing (Fig. 2b), was located in the effect regions of positive precipitation-vegetation relationship (Fig. 1), and the correlation between NDVI

15 variability and precipitation variability was positive (Fig. 3b). The fastest decrease of NDVI rate was distributed in the northeast of China (Fig. 2a). On one hand, the dynamics response to temperature variability was negative there, which was located in the effect regions of negative temperature-vegetation relationship. On the other hand, the precipitation trend in this area was increasing. But the dynamic response patterns to precipitation variability were discontinuous.

According to the upper analysis, it is indicated that the effect of hydrothermal combination on vegetation activity is

20 very important in the context of warming. The high warming rate will lead to excessive evapotranspiration of vegetation and soil moisture, which may further cause to drought and restrain the vegetation growth. Meanwhile, most of the variations in precipitation rate can adjust the hydrothermal conditions for vegetation growth and promote its activity to a certain extent. Moreover, when the dynamics response to climatic variability is consistent with the effect regions, this kind of climatic factor and its variability will play an important role on the vegetation activity, combined Fig. 1 with Fig. 3.

\section{3.2 Future scenarios of climate-vegetation correlations and the varying patterns}

\subsubsection{Future responding patterns for annual average of vegetation activity}

As the temperature rises, the vegetation response to temperature is more and more evident in the Tibetan Plateau, and the effect regions will turn to a positive temperature-vegetation correlation, the eastern part of which in the past will be moving southward (Fig. 4a). In several parts of the Loess Plateau and Inner Mongolia Plateau, the effect regions will be changed

30 because the influence of positive temperature-vegetation correlation will gradually surpass that of precipitation. The temperature response will transform from negative to positive correlation in the Sanjiang Plain-Changbai Mountain of northeast China, which indicates that the hydrothermal condition has been improved in these areas. 
Earth Syst. Dynam. Discuss., doi:10.5194/esd-2017-13, 2017

Manuscript under review for journal Earth Syst. Dynam.

Discussion started: 22 February 2017

(c) Author(s) 2017. CC-BY 3.0 License.

The effect regions of positive precipitation-vegetation correlation have been extending southward to the Hubei and Hunan Plain and Sichuan Basin, and in the south of $25^{\circ} \mathrm{N}$ the effect regions will be positive temperature-vegetation correlation (Fig. 4a). In the Junggar Basin the positive correlation of precipitation is weaker than the past and the effect regions will turn to a negative correlation of temperature, indicating the worsened drought condition in the future. In addition,

5 the effect regions of others will be increasing in the central of the Northeast Plain and southeast of the North China Plain, which indicates that the effect regions will become more complicated in these areas in the future.

\subsubsection{Future responding patterns for annual variability of vegetation activity}

Compared with the past, the response to temperature variability will turn to a positive correlation in the Yunnan-Guizhou Plateau, Tibet Plateau and most areas of east China, while it will turn to negative in the Inner Mongolia and east Qinghai

10 province (Fig. 4b). However, with the complex interaction of water and heat, the spatiotemporal variation of precipitation in the future will be more intense, which makes the dynamic patterns of precipitation more fragmented (not shown).

Precipitation trend will be changing from a downward trend to upward from the Sichuan Basin to the east of YunnanGuizhou Plateau (Fig. 5b), where the effect regions will turn to a positive precipitation-vegetation relationship (Fig. 4a). In the east of Yunnan-Guizhou Plateau, the responses to temperature and precipitation variability are positive, which reveals

15 that both temperature and precipitation will be conducive to vegetation activity in these areas. But in the Sichuan Basin, the response to temperature variability is negative, so the increasing precipitation will play a greater role there on vegetation activity.

In contrast, precipitation trend from upward to downward has been mainly distributed in the North China Plain and the south coast (Fig. 5b). The reason for NPP decreasing in North China Plain (Fig. 5a) is that the precipitation reduction will

20 lead to the drought aggravated. And the response to precipitation variability will turn to a negative relationship in most parts, which means that the faster the precipitation decreasing rate, the slower rate of NPP decreasing. It may indicate that the vegetation have been adapted to the warm and dry environment gradually. In the south coast, however, NPP will be continuous increasing there (Fig. 5a). The effect regions will turn to a positive temperature-vegetation relationship, which is consistent with the response to temperature variability. It is indicated that an increase in warming rate will play a greater role

25 there. At the same time, the response to precipitation variability will be negative relationship in the future. That is, the faster the precipitation rate decreasing, the more rapid increased rate of NPP. Therefore, both temperature and precipitation variability will promote the vegetation activity together in these areas.

\subsection{Response patterns and processes at different stages in the future}

Furthermore, in order to discuss the process of vegetation response to climate change, the transfer of spatial patterns and its

30 control mechanism from an uptrend period to a downtrend of NPP have been detected. Then we tried to solve the question whether the change of vegetation trend in different regions is transitional and explore the threshold when the trend will be varying. 
Earth Syst. Dynam. Discuss., doi:10.5194/esd-2017-13, 2017

Manuscript under review for journal Earth Syst. Dynam.

Discussion started: 22 February 2017

(c) Author(s) 2017. CC-BY 3.0 License.

\subsubsection{Stages classification and spatial changes of effect regions}

From the inter-annual variations of NPP in the next 30 years (Fig. 6a), it shows a more significant downward trend after the year of 2039 (Fig. 6b). Then the accumulative anomaly of NPP in 2021-2038 is illustrated in Fig. 6c. It is shown that there is an increasing trend prior to the year of 2030, and a decreasing trend after 2030. The inflexion point of the NPP change is

52030 in this period. Therefore, we selected an upward trend (T1:2021-2030) and a downward of NPP (T2:2039-2050) as two future periods in this paper.

The effect regions of climatic factors on vegetation in different periods are illustrated in Fig. 7, and its change areas are summarized in Table 2. Compared with T1, the positive correlation of precipitation will be more and more obvious near the middle and lower reaches of the Yangtze River in T2 period. However, the precipitation there will be decreasing

10 dramatically during T2. So the increase of temperature will accentuate the importance of moisture, which is the main reason for the NPP decline there. The negative correlation with temperature has been reflected in the north China, where the increasing temperature will accelerate the evapotranspiration. Negative precipitation-vegetation correlation will begin appearing in the north of Greater Khingan Mountains and the east of Yunnan-Guizhou Plateau, in which the variation trend of precipitation is unevenly and the upward trend of NPP will be slightly weaker than T1. Moreover, the effect regions of

15 others will restrain the vegetation activity in the Jiangnan Hills, Sichuan Basin and the Western Sichuan Plateau, which indicates that the effect regions will become more complicated.

For the dynamics responding patterns, the negative correlation with temperature variability will almost extend nationwide. It can be seen that the warming rate will become the main reason for inhibiting vegetation activity. Precipitation variability will still reflect the characteristics of uneven distribution. Negative correlation regions will increase in northern

20 parts of China, in which the applicability of vegetation to water shortage environment will be enhanced. In the southern parts, however, the negative correlation of precipitation variability will have been reduced. Warm and dry environments will continue to limit vegetation activity.

\subsubsection{Quantitative detection on variation in vegetation trends}

Compared with precipitation, the temperature will be changing regularly along with the vegetation trend, which clearly 25 reflects its transformation. Theoretically the NPP response is a bell-shaped with temperature change (Fig. 8). Therefore, the NPP trends in T1 and T2 were compared and 6 regions have been divided based on the difference (Fig. 9). Changes in temperature, precipitation and their variability in different areas have been given in Table3. R1, where NPP will transform from rising to declining with more warming $\left(0.70 \pm 0.29^{\circ} \mathrm{C}\right)$, is mainly distributed in the Northeast and North China Plain. R3 is mainly distributed in the south of China and the upward trend of NPP there will have slowed down. R6, indicating that 30 vegetation activity will adapt to the high temperature and low precipitation, is widely distributed in the northwest arid regions. As is shown in Fig. 11, there is an obvious spatial continuity between different regions (R1and R3, R5; R6 and R5; $\mathrm{R} 4$ and R3 etc.). It is indicated that the trend of vegetation change is a dynamic and continuous process, which the 
Earth Syst. Dynam. Discuss., doi:10.5194/esd-2017-13, 2017

Manuscript under review for journal Earth Syst. Dynam.

Discussion started: 22 February 2017

(c) Author(s) 2017. CC-BY 3.0 License.

development order is R4-R3-R1-R5-R6 respectively. That is, the uptrend of NPP will slow down, enter a downward trend and begin to accelerate, and finally adapt to the harsh environments. When the climatic conditions improve, the vegetative activity may be restored to the previous state (R2).

In order to study the variation process of vegetation and the corresponding temperature rising, the average NPP and its trend variation $(\triangle N P P$ and $\Delta N t)$ divided by the temperature range of $0.2^{\circ} \mathrm{C}$, were calculated and fitted by nonlinearly curves in the specified region (Fig. 10). It should be noted that $\triangle N P P$ represents the variation of NPP and $\triangle N t$ expresses the variation of NPP variability from $\mathrm{T} 1$ to $\mathrm{T} 2$.

$\mathrm{R} 4$ and R3 occupy most regions of southwest China. NPP will continue to increase and $\triangle N P P$ will first increase (R4) and then decrease (R3) as the temperature increases (Fig. 9). The increase of $\Delta N t$ will be from fast to slow and then decrease

10 after A2 ( $\left.\triangle N t=\frac{\partial \Delta N P P}{\partial \Delta T}=\frac{\partial^{2} N P P}{\partial \Delta T^{2}}=0\right)$, which is the turning point during the process of R4 to R3 (Fig. 10a). It denotes that NPP uptrend rate begins to decrease when the temperature is raised about $0.33^{\circ} \mathrm{C}\left( \pm 0.01^{\circ} \mathrm{C}\right)$ in the southwest. When the temperature keeps increasing more than A3(0.475 $\left.\pm 0.01{ }^{\circ} \mathrm{C}\right)$, NPP may show a tendency to adapt to adverse environment, while NPP will be in the process of turning into a growth trend with the improvement of environmental conditions before A1.

Most parts of the Loess Plateau will be located in the change of R5 to R6. NPP will continue to decrease with $\triangle N P P$

15 first decrease (R5) and then increase (R6) (Fig. 9). The decrease of $\Delta N t$ will be from fast to slow and then increase after B ( $\triangle N t=\frac{\partial \Delta N P P}{\partial \Delta T}=\frac{\partial^{2} N P P}{\partial \Delta T^{2}}=0$ ), which will be the turning point from R5 to R6 (Fig. 10b). It means that vegetation in the Loess Plateau will begin to improve the water use efficiency (WUE) in order to adapt to harsh environment if the temperature is raised about $0.43^{\circ} \mathrm{C}\left( \pm 0.01^{\circ} \mathrm{C}\right)$.

At last, NPP will be experiencing a process from increasing to decreasing in the northeast (R3-R1-R5), $\triangle N P P$ will

20 continue to decrease and then turn into downtrend after $\mathrm{C} 2\left(\triangle N P P=\frac{\partial N P P}{\partial \Delta T}=0\right)$, which will be the tipping point of vegetation activity from rise to decline (Fig. 10c). That is, the vegetation trend will be reversed when the temperature will be raised more than $0.83^{\circ} \mathrm{C}\left( \pm 0.01^{\circ} \mathrm{C}\right)$ in the northeast and enter into the adaptation stage after the temperature is over $1.02 \pm 0.01{ }^{\circ} \mathrm{C}$ (C3), while it reflects the trend of previous process (R4) before $\mathrm{C} 1$.

\section{Discussion}

\section{$25 \quad 4.1$ Responding mechanism}

From the past to future, it can be seen that the response of vegetation activity to climate change is more and more obvious, which is consistent with the research results in other areas (Piao et al., 2011; Urban, 2015). However, climate-vegetation relationship is complex with nonlinear characteristics. Specifically, before the optimum temperature for photosynthesis, a temperature rise will promote vegetation activity by an accelerated release of nutrients and improved availability from the soil (Michaletz et al., 2014), such as the Tibetan Plateau in the future. When overpass this temperature, however, the 
Earth Syst. Dynam. Discuss., doi:10.5194/esd-2017-13, 2017

Manuscript under review for journal Earth Syst. Dynam.

Discussion started: 22 February 2017

(c) Author(s) 2017. CC-BY 3.0 License.

respiration will be promoted and accelerate the nutrients consumption, especially in the effect regions of negative temperature-vegetation relationship in the northwest of China. On the other hand, water shortage is not conducive to the transport of nutrients, thereby reducing the accumulation of organic matter (Brohan et al., 2006). So the precipitation variation can adjust the vegetation activity to a certain extent. However, vegetation in several northern parts may gradually adapt to the drought because the warming there will weaken the varying rate of photosynthesis and respiration, which cause the NPP downtrend slowed.

\subsection{Spatial heterogeneity}

In this study, the effect region was defined and applied to identify the dominated climatic factors for vegetation activity in different areas of China during the past and future 30 years. Corresponding to future global warming, the importance of

10 available water for vegetation activity will be more prominent, which causes the effect regions of positive precipitationvegetation relationship moving southward in the future. On the other hand, there may be different explanations for the same type of correlation in different regions, for example, in the Tibetan Plateau and parts of North China Plain, the relationships between vegetation and temperature are both positive in the future. The response to temperature is stronger than that of precipitation in the former because of the low background temperature and precipitation trend will increase in the future

15 (Wang et al., 2015). The increasing temperature will be more beneficial to the photosynthesis. But in the latter, the effect of precipitation on vegetation will be more prominent due to the high background temperature and decreasing precipitation trend (Xu and Wang, 2016). Therefore, the temporal and spatial distribution of background climate, moisture and heat is an important reason for the heterogeneity of vegetation activity.

GWR can better simulate the spatial non-stationary relationship between vegetation activity and climatic change, which

20 is difficult to predict due to the combination of different factors (Kupfer and Farris, 2007). Compared with the approach based on traditional correlation analysis, GWR has a better ability to deal with regional difference in responding mechanism or processes, which is essential for making policy to suit adaptation measures to local situation. Moreover, execution of spatial relationship modelling, together with application of varying rate in GWR, significantly reduced multi-collinearity. Thus, based on the geographic theory of process and pattern coupling, the GWR regression to climate variability can better

25 highlight the mechanism and dynamic response between climate change and vegetation activity, which is more explanatory than the previous studies on climate change trends.

\subsection{Uncertainties}

It is necessary to point out that our research for the continuous process of vegetation change was only based on the detection of a phenomenon at regional scales. Relevant mechanisms, especially the adaptation of drought and tipping point of NPP 30 trend, still need further study. On the other hand, only the regression relationship between vegetation and climatic factors were analyzed in this paper. Besides natural environmental factors, human activity is also important to affect the ecosystem dynamics. For example, ecological restoration policy, such as the Three-North Shelter Forest Program, promoted vegetation 
Earth Syst. Dynam. Discuss., doi:10.5194/esd-2017-13, 2017

Manuscript under review for journal Earth Syst. Dynam.

Discussion started: 22 February 2017

(c) Author(s) 2017. CC-BY 3.0 License.

greening in the Loess Plateau during 2000-2010 (Lu et al., 2015). From the perspective of human-environment relationships, the human activity scenarios need to be incorporated into the GWR model in order to obtain more objective results in the next step, which provide the basis and support for the response to climate change, and propose adaptation and mitigation strategies in the future.

\section{Conclusions}

Vegetation activity in the north China was and will be restricted by water. The increase of precipitation can promote the vegetation activity, while the increase of temperature may cause the evapotranspiration to intensify that increase the drought trend (Feng et al., 2016). In the southern parts, however, the vegetation response to temperature is more closely (Fang et al., 2002). The precipitation and soil moisture content are abundant there, so the temperature increasing is beneficial to the

10 extension of growth season and the organic matter accumulation for vegetation. While in the northwest arid regions, the effect regions will transform from the positive precipitation-vegetation relationship to the negative temperature-vegetation. And the Tibetan Plateau will become a positive temperature-vegetation correlation. Moreover, the effect regions of positive temperature-vegetation relationship will increase in the Northeast Plain and the North China Plain.

The response of vegetation dynamic to temperature variability was the negative in most of China in the past 3 decades.

15 It is indicated that vegetation growth will be restrained by high warming rate. While in the next 30 years, this response will turn to a positive relationship in the east and southwest China. The response to precipitation variability may mediate vegetation response to temperature through interaction with water availability.

Vegetation activity will have a downtrend expression after the year of 2039. From the NPP trend rising (T1) and declining period (T2) in the next 30 years, it can be concluded that the inhibition of vegetation activity will be enhanced with

20 increasing temperature. The effect regions of a positive temperature-vegetation correlation will be decreasing but the negative correlation areas will increase more than $90 \%$. Meanwhile, the negative correlation of temperature variability will be increasing. Furthermore, the vegetation change trend in the future is dynamic and continuous. With the precipitation decreasing, vegetation in the northern parts may gradually adapt to warm and dry conditions, while it will continue to be limited by moisture in the southern parts.

25 Acknowledgements. This research was financially supported by the National Natural Science Foundation of China (Grant No. 41530749, 41671098, 31370442) and the National Basic Research Program of China (Grant No. 2015CB452702). We acknowledge National Climate Center for providing the data of their simulations by regional climate model.

\section{References}

Baez, S., Collins, S. L., Pockman, W. T., Johnson, J. E., and Small, E. E.: Effects of experimental rainfall manipulations on

Chihuahuan Desert grassland and shrubland plant communities, Oecologia, 172, 1117-1127, 2013. 
Earth Syst. Dynam. Discuss., doi:10.5194/esd-2017-13, 2017

Manuscript under review for journal Earth Syst. Dynam.

Discussion started: 22 February 2017

(c) Author(s) 2017. CC-BY 3.0 License.

Brohan, P., Kennedy, J. J., Harris, I., Tett, S. F. B., and Jones, P. D.: Uncertainty estimates in regional and global observed temperature changes: A new data set from 1850, J. Geophys. Res-Atmos., 111, 121-133, 2006.

Chen, Y., Zhang, W., Yang, T., Zhao, G., and Wang, S.: The change characteristics of net primary production in different vegetation types in China, Journal of Fudan University (Natural Science) (in Chinese with English abstract), 51, 377-381,

52012.

de Jong, R., Schaepman, M. E., Furrer, R., De Bruin, S., and Verburg, P. H.: Spatial relationship between climatologies and changes in global vegetation activity, Glob. Change Biol., 19, 1953-1964, 2013.

Del Grosso, S., Parton, W., Stohlgren, T., Zheng, D., Bachelet, D., Prince, S., Hibbard, K., and Olson, R.: Global potential net primary production predicted from vegetation class, precipitation, and temperature, Ecology, 89, 2117-2126, 2008.

10 Dong, B. and Sutton, R.: Dominant role of greenhouse-gas forcing in the recovery of Sahel rainfall, Nat. Clim. Chang., 5, 757-760, 2015.

Duo, A., Zhao, W., Qu, X., Jing, R., and Xiong, K.: Spatio-temporal variation of vegetation coverage and its response to climate change in North China plain in the last 33 years, Int. J. Appl. Earth Obs., 53, 103-117, 2016.

Fang, J., Piao, S., He, J., and Ma, W.: Increasing terrestrial vegetation activity in China, 1982-1999, Sci. China Ser. C., 47,

$15 \quad 229-240,2004$.

Fang, J. Y., Song, Y. C., Liu, H. Y., and Piao, S. L.: Vegetation-climate relationship and its application in the division of vegetation zone in China, Acta Bot. Sin., 44, 1105-1122, 2002.

Fay, P. A., Kaufman, D. M., Nippert, J. B., Carlisle, J. D., and Harper, C. W.: Changes in grassland ecosystem function due to extreme rainfall events: implications for responses to climate change, Glob. Change Biol., 14, 1600-1608, 2008.

20 Feng, X., Fu, B., Piao, S., Wang, S., Ciais, P., Zeng, Z., Lü, Y., Zeng, Y., Li, Y., Jiang, X., and Wu, B.: Revegetation in China’s Loess Plateau is approaching sustainable water resource limits, Nat. Clim. Chang., 6, 1019-1022, 2016.

Fotheringham, A. S., Brunsdon, C. F., and Charlton, M. E.: Geographically Weighted Regression: The Analysis of Spatially Varying Relationships. West Sussex, Am. J. Agr. Econ., 86, 2002.

Hoover, D. L., Knapp, A. K., and Smith, M. D.: Resistance and resilience of a grassland ecosystem to climate extremes,

25 Ecology, 95, 2646-2656, 2014.

Krishnaswamy, J., John, R., and Joseph, S.: Consistent response of vegetation dynamics to recent climate change in tropical mountain regions, Glob. Change Biol., 20, 203-215, 2014.

Kupfer, J. A. and Farris, C. A.: Incorporating spatial non-stationarity of regression coefficients into predictive vegetation models, Landscape Ecol., 22, 837-852, 2007.

30 Liu, Y., Ju, W., He, H., Wang, S., Sun, R., and Zhang, Y.: Changes of net primary productivity in China during recent 11 years detected using an ecological model driven by MODIS data, Front. Earth Sci., 7, 112-127, 2013.

Lu, Y., Zhang, L., Feng, X., Zeng, Y., Fu, B., Yao, X., Li, J., and Wu, B.: Recent ecological transitions in China: greening, browning, and influential factors, Sci. Rep., 5, 8732, 2015.

Mao, D., Wang, Z., Luo, L., and Ren, C.: Integrating AVHRR and MODIS data to monitor NDVI changes and their 
Earth Syst. Dynam. Discuss., doi:10.5194/esd-2017-13, 2017

Manuscript under review for journal Earth Syst. Dynam.

Discussion started: 22 February 2017

(c) Author(s) 2017. CC-BY 3.0 License.

relationships with climatic parameters in Northeast China, Int. J. Appl. Earth Obs., 18, 528-536, 2012.

Michaletz, S. T., Cheng, D., Kerkhoff, A. J., and Enquist, B. J.: Convergence of terrestrial plant production across global climate gradients, Nature, 512, 39-43, 2014.

$\mathrm{Ni}$, J.: Net primary productivity in forests of China: scaling-up of national inventory data and comparison with model

5 predictions, Forest Ecol. Manag., 176, 485-495, 2003.

Peng, S., Piao, S., Ciais, P., Myneni, R. B., Chen, A., Chevallier, F., Dolman, A. J., Janssens, I. A., Penuelas, J., Zhang, G., Vicca, S., Wan, S., Wang, S., and Zeng, H.: Asymmetric effects of daytime and night-time warming on Northern Hemisphere vegetation, Nature, 501, 88-92, 2013.

Piao, S., Ciais, P., Friedlingstein, P., Peylin, P., Reichstein, M., Luyssaert, S., Margolis, H., Fang, J., Barr, A., Chen, A.,

10 Grelle, A., Hollinger, D. Y., Laurila, T., Lindroth, A., Richardson, A. D., and Vesala, T.: Net carbon dioxide losses of northern ecosystems in response to autumn warming, Nature, 451, 49-52, 2008.

Piao, S., Nan, H., Huntingford, C., Ciais, P., Friedlingstein, P., Sitch, S., Peng, S., Ahlstrom, A., Canadell, J. G., Cong, N., Levis, S., Levy, P. E., Liu, L., Lomas, M. R., Mao, J., Myneni, R. B., Peylin, P., Poulter, B., Shi, X., Yin, G., Viovy, N., Wang, T., Wang, X., Zaehle, S., Zeng, N., Zeng, Z., and Chen, A.: Evidence for a weakening relationship between 15 interannual temperature variability and northern vegetation activity, Nat. Commun., 5, 5018, 2014.

Piao, S., Wang, X., Ciais, P., Zhu, B., Wang, T., and Liu, J.: Changes in satellite-derived vegetation growth trend in temperate and boreal Eurasia from 1982 to 2006, Glob. Change Biol., 17, 3228-3239, 2011.

Reyer, C. P. O., Leuzinger, S., Rammig, A., Wolf, A., Bartholomeus, R. P., Bonfante, A., de Lorenzi, F., Dury, M., Gloning, P., Abou Jaoude, R., Klein, T., Kuster, T. M., Martins, M., Niedrist, G., Riccardi, M., Wohlfahrt, G., de Angelis, P., de Dato,

20 G., Francois, L., Menzel, A., and Pereira, M.: A plant's perspective of extremes: terrestrial plant responses to changing climatic variability, Glob. Change Biol., 19, 75-89, 2013.

Robertson, T. R., Bell, C. W., Zak, J. C., and Tissue, D. T.: Precipitation timing and magnitude differentially affect aboveground annual net primary productivity in three perennial species in a Chihuahuan Desert grassland, New Phytol., 181, 230-242, 2009.

25 Seddon, A. W. R., Macias-Fauria, M., Long, P. R., Benz, D., and Willis, K. J.: Sensitivity of global terrestrial ecosystems to climate variability, Nature, 531, 229-243, 2016.

Sitch, S., Smith, B., Prentice, I. C., Arneth, A., Bondeau, A., Cramer, W., Kaplan, J. O., Levis, S., Lucht, W., and Sykes, M. T.: Evaluation of ecosystem dynamics, plant geography and terrestrial carbon cycling in the LPJ dynamic global vegetation model, Glob. Change Biol., 9, 161-185, 2003.

30 Tucker, C. J., Pinzon, J. E., Brown, M. E., Slayback, D. A., Pak, E. W., Mahoney, R., Vermote, E. F., and El Saleous, N.: An extended AVHRR 8-km NDVI dataset compatible with MODIS and SPOT vegetation NDVI data, Int. J. Remote Sens., 26, 4485-4498, 2005.

Urban, M. C.: Accelerating extinction risk from climate change, Science, 348, 571-573, 2015.

Wang, C., Guo, H., Zhang, L., Liu, S., Qiu, Y., and Sun, Z.: Assessing phenological change and climatic control of alpine 
Earth Syst. Dynam. Discuss., doi:10.5194/esd-2017-13, 2017

Manuscript under review for journal Earth Syst. Dynam.

Discussion started: 22 February 2017

(c) Author(s) 2017. CC-BY 3.0 License.

grasslands in the Tibetan Plateau with MODIS time series, Int. J. Biometeorol., 59, 11-23, 2015.

Wang, Q., Ni, J., and Tenhunen, J.: Application of a geographically-weighted regression analysis to estimate net primary production of Chinese forest ecosystems, Global Ecol. Biogeogr., 14, 379-393, 2005.

Wang, Q., Zhang, Q. P., and Zhou, W.: Grassland Coverage Changes and Analysis of the Driving Forces in Maqu County,

5 Physcs. Proc., 33, 1292-1297, 2012.

Wang, Q., Zhao, P., Ren, H., and Kakubari, Y.: Spatiotemporal dynamics of forest net primary production in China over the past two decades, Global Planet. Change, 61, 267-274, 2008.

Wang, T., Lin, X., Liu, Y., Dantec-Nédélec, S., and Ottlé, C.: Causes of uncertainty in China's net primary production over the 21st century projected by the CMIP5 Earth system models, Int. J. Climatol., 36, 2323-2334, 2016.

10 Wright, C. K., de Beurs, K. M., and Henebry, G. M.: Combined analysis of land cover change and NDVI trends in the Northern Eurasian grain belt, Front. Earth Sci., 6, 177-187, 2012.

Xu, H.-j. and Wang, X.-p.: Effects of altered precipitation regimes on plant productivity in the arid region of northern China, Ecol. Inform., 31, 137-146, 2016.

Zeppel, M. J. B., Wilks, J. V., and Lewis, J. D.: Impacts of extreme precipitation and seasonal changes in precipitation on

15 plants, Biogeosciences, 11, 3083-3093, 2014.

Zhang, K., Kimball, J. S., Nemani, R. R., Running, S. W., Hong, Y., Gourley, J. J., and Yu, Z.: Vegetation Greening and Climate Change Promote Multidecadal Rises of Global Land Evapotranspiration, Sci. Rep., 5, 75-77, 2014.

Zhao, D., Wu, S., and Yin, Y.: Responses of Terrestrial Ecosystems' Net Primary Productivity to Future Regional Climate Change in China, Plos One, 8, 2013.

20 Zhao, M. and Running, S. W.: Response to Comments on "Drought-Induced Reduction in Global Terrestrial Net Primary Production from 2000 Through 2009”, Science, 333, 1093-1093, 2011.

Table 1. Comparisons of average simulated NPP in this paper and that in other studies for different vegetation types $\left(\mathrm{g} \mathrm{C} / \mathbf{m}^{2} \cdot \mathbf{a}\right)$.

\begin{tabular}{ccccc}
\hline \multirow{2}{*}{ Types } & \multicolumn{2}{c}{ This paper } & \multicolumn{2}{c}{ Literature } \\
\cline { 2 - 5 } & $\begin{array}{c}\text { LPJ-DGVM } \\
\text { Simulated }\end{array}$ & SD & $\begin{array}{c}\text { Multi-models } \\
\text { Simulated }\end{array}$ & Observations \\
\hline $\begin{array}{c}\text { Tropical broadleaved } \\
\text { evergreen/monsoon forests }\end{array}$ & 743.2 & 104.2 & $\begin{array}{c}1602.8 \\
(912.0 \sim 2450.0)\end{array}$ & 1808.5 \\
Broadleaved evergreen forests & 693.4 & 111.6 & 898.0 & \multirow{2}{*}{$\begin{array}{c}(484.2 \sim 1450.0) \\
\text { Needleleaved evergreen forests }\end{array}$} \\
& 658.4 & 82.4 & 584.3 & \\
& & & $(347.0 \sim 1180.0)$ & 606.1
\end{tabular}


Earth Syst. Dynam. Discuss., doi:10.5194/esd-2017-13, 2017

Manuscript under review for journal Earth Syst. Dynam.

Discussion started: 22 February 2017

(c) Author(s) 2017. CC-BY 3.0 License.

$\begin{array}{ccccc}\text { Broadleaved deciduous forests } & 558.1 & 122.1 & 551.6 & 754.3 \\ \text { Needleleaved deciduous forests } & 467.3 & 150.9 & (282.1 \sim 928.0) & \\ & & & (270.7 \sim 727.3) & 490.0 \\ \text { Scrubs } & 575.7 & 181.7 & 379.9 & \\ & & & (127.5 \sim 823.0) & 364.0 \\ \text { Grasslands } & 266.4 & 242.0 & 323.6 & \\ & & & (103.4 \sim 690.9) & 289.5\end{array}$

Table 2. Change area of the effect regions of climatic factors in $T 1$ and $T 2$ periods $\left(10^{4} \mathrm{~km}^{2}\right)$.

\begin{tabular}{llllll}
\hline & $\mathrm{T}_{-}$Positive & $\mathrm{T}_{-}$Negative & $\mathrm{P}_{-}$Positive & $\mathrm{P}_{-}$Negative & Others \\
\hline $\mathrm{T} 1$ & 364.58 & 54.04 & 378.26 & 36.49 & 22.11 \\
$\mathrm{~T} 2$ & 213.69 & 103.16 & 421.42 & 59.30 & 68.77 \\
Variation \% & -41.39 & 90.90 & 11.41 & 62.51 & 211.04 \\
\hline
\end{tabular}

Table 3. Changes of climatic factors in different regions during $\mathrm{T} 1$ to $\mathrm{T} 2$ period.

\begin{tabular}{ccccccc}
\hline & $\mathrm{R} 1$ & $\mathrm{R} 2$ & $\mathrm{R} 3$ & $\mathrm{R} 4$ & $\mathrm{R} 5$ & $\mathrm{R} 6$ \\
\hline Area $\left(10^{4} \mathrm{~km}^{2}\right)$ & 278.96 & 73.69 & 187.73 & 95.79 & 105.97 & 110.18 \\
$\begin{array}{c}\text { T change }\left({ }^{\circ} \mathrm{C}\right) \\
\text { Tv change }\end{array}$ & 0.703 & 0.498 & 0.505 & 0.453 & 0.500 & 0.510 \\
$\quad\left({ }^{\circ} \mathrm{C} / \mathrm{a}\right)$ & 0.051 & 0.063 & 0.021 & 0.009 & 0.095 & 0.083 \\
$\begin{array}{c}\mathrm{P} \text { change }(\mathrm{mm}) \\
\text { Pv change } \\
(\mathrm{mm} / \mathrm{a})\end{array}$ & -6.941 & -24.735 & -21.763 & -8.518 & 14.894 & 12.040 \\
\hline
\end{tabular}

5 Note: $\mathrm{T}$-Temperature; $\mathrm{Tv}$-Temperature variability; $\mathrm{P}$ —Precipitation; $\mathrm{Pv}-$ Precipitation variability 
Earth Syst. Dynam. Discuss., doi:10.5194/esd-2017-13, 2017

Manuscript under review for journal Earth Syst. Dynam.

Discussion started: 22 February 2017

(c) Author(s) 2017. CC-BY 3.0 License.

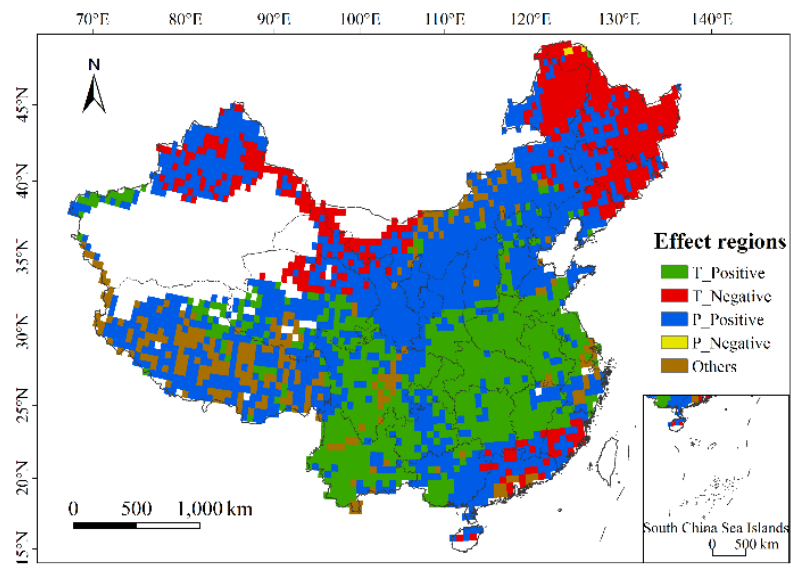

Figure 1: Effect regions of climatic factors from GWR model over the past 32 years.
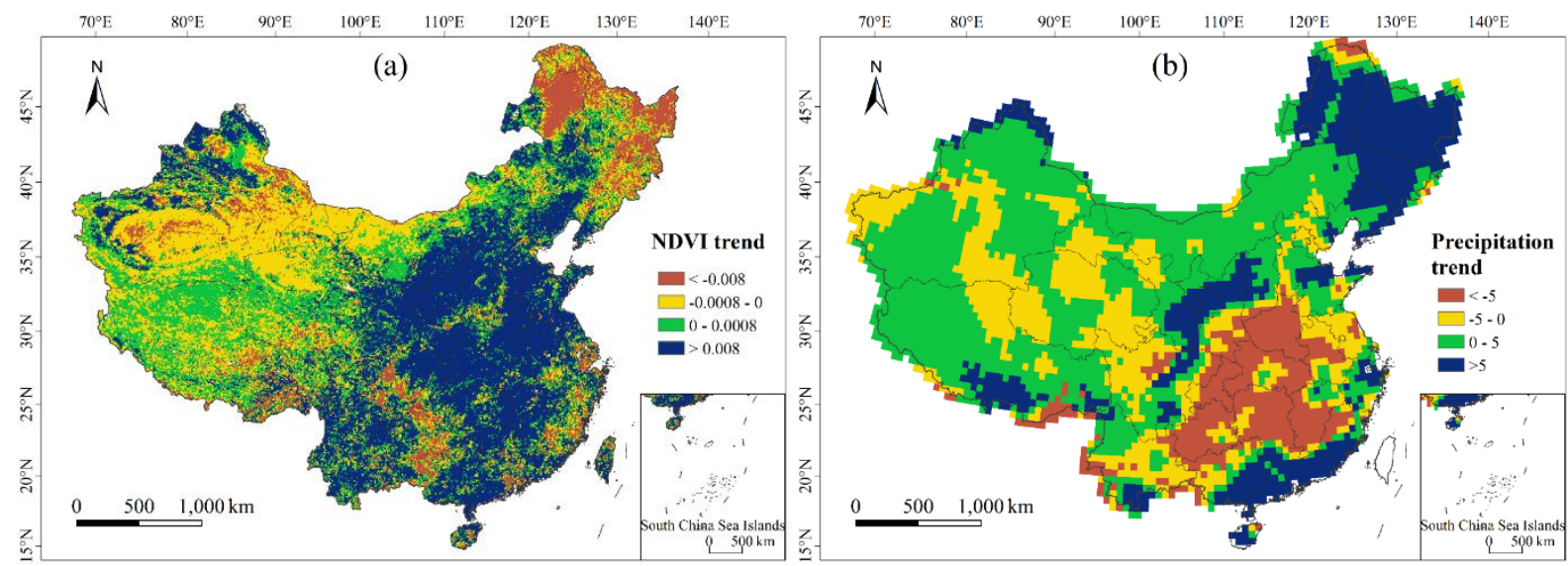

Figure 2: Spatial patterns of NDVI trend (a) and precipitation trend (b) during 1982-2013.
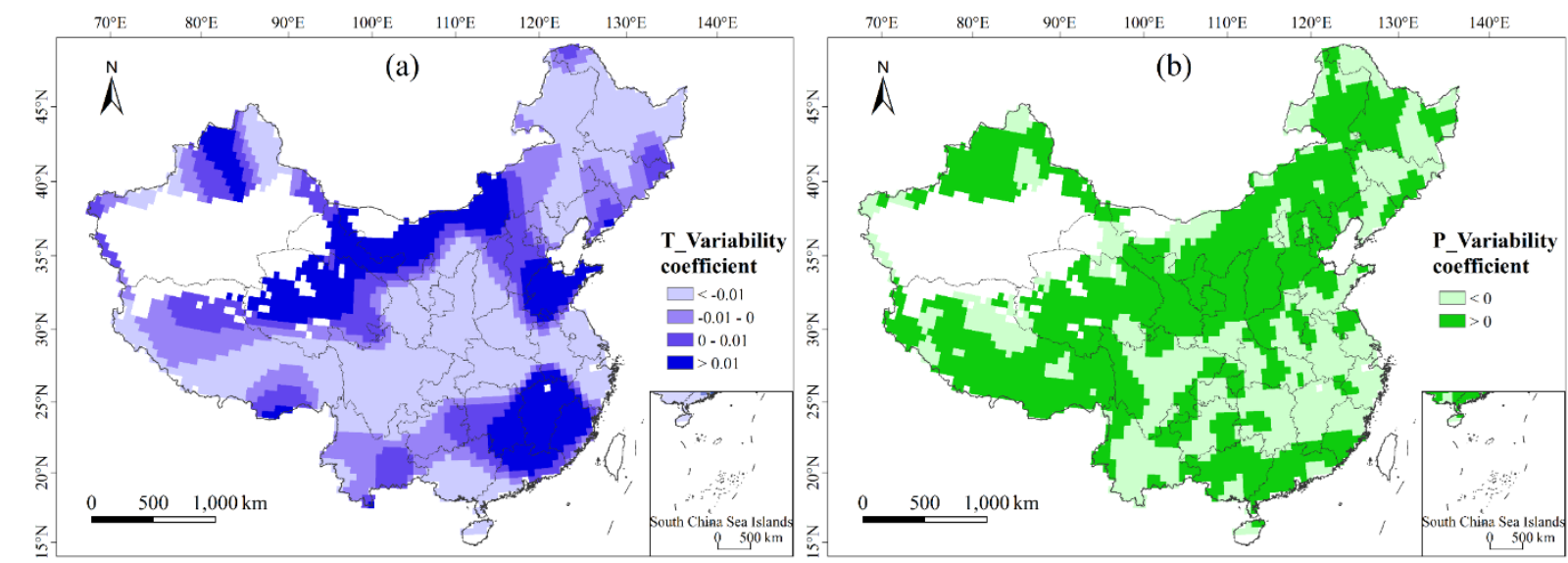

Figure 3: Spatial regression coefficients between NDVI variability and climate variability (temperature variability (a), precipitation variability (b)) from GWR model over the past 32 years. 
Earth Syst. Dynam. Discuss., doi:10.5194/esd-2017-13, 2017

Manuscript under review for journal Earth Syst. Dynam.

Discussion started: 22 February 2017

(c) Author(s) 2017. CC-BY 3.0 License.

(c) $($ i)
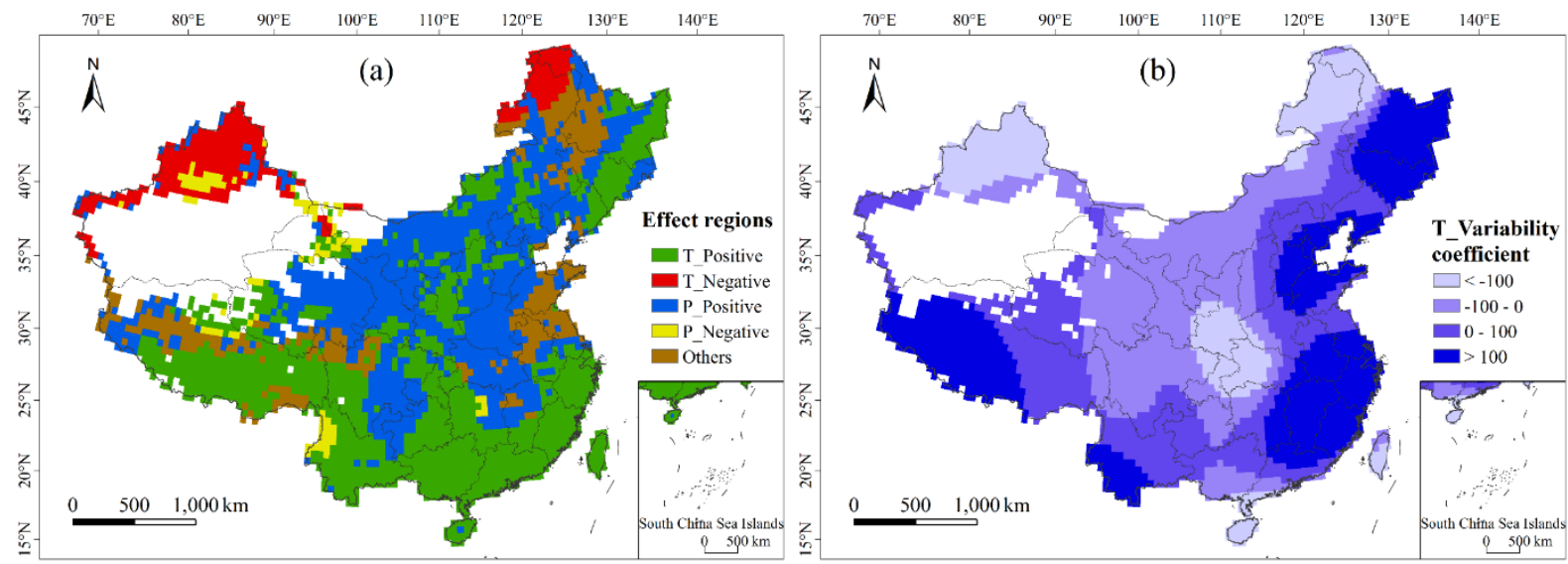

Figure 4: Effect regions of climatic factors (a) and spatial regression coefficients between NPP variability and temperature variability (b) from GWR model for the future scenario.
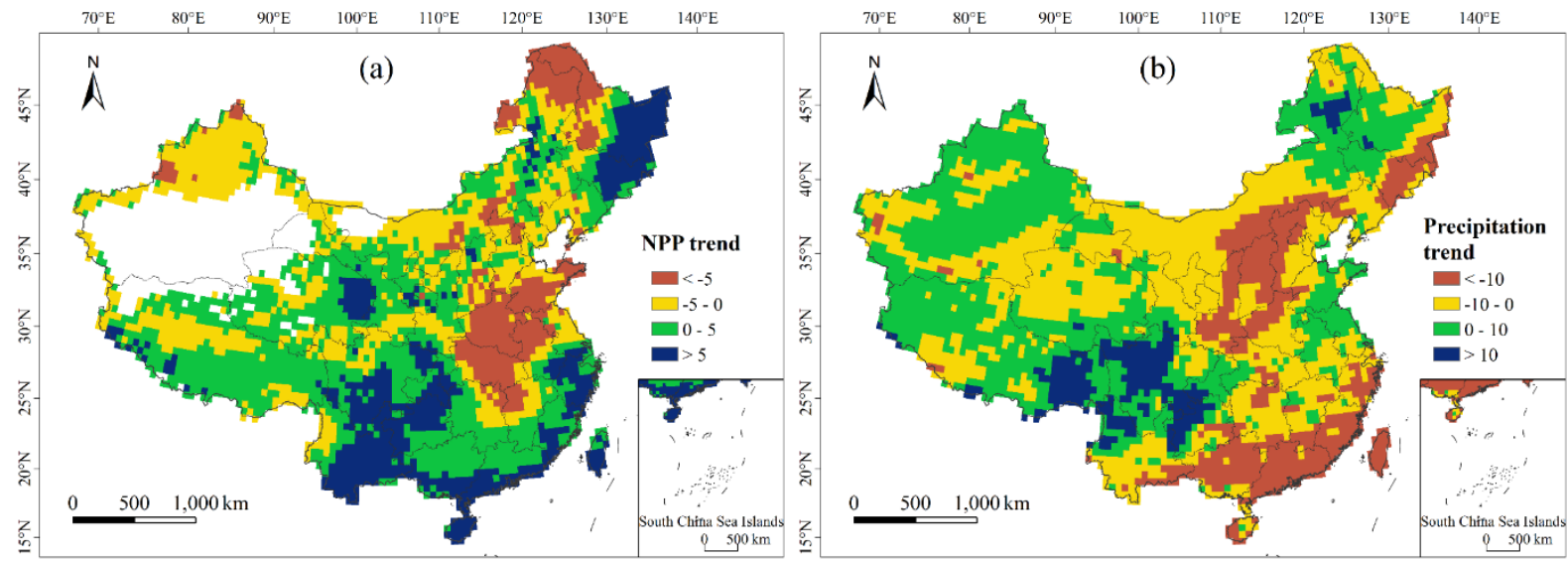

5 Figure 5: Spatial patterns of NPP (a) and precipitation trend (b) during 2021-2050.
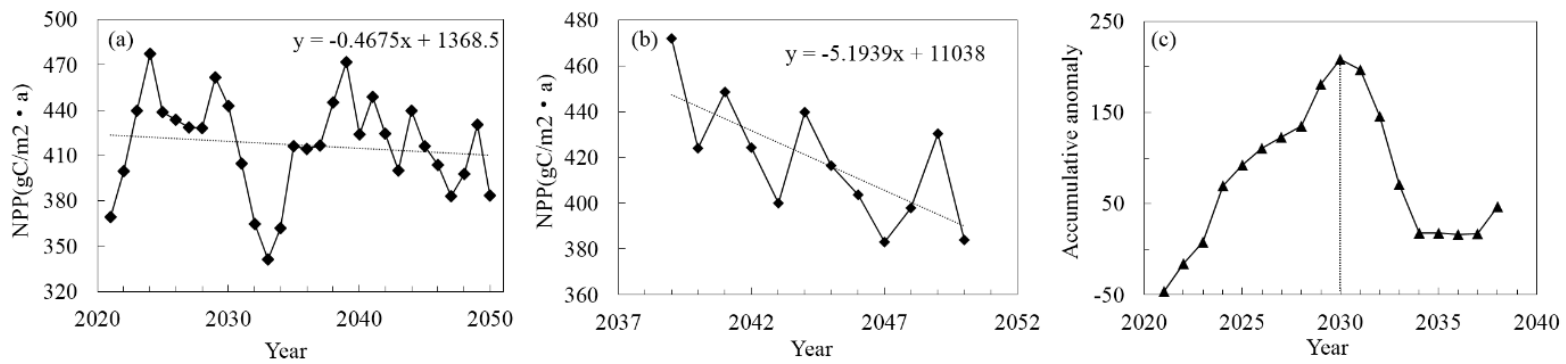

Figure 6: Inter-annual variations of NPP in China (a:2021-2050; b:2039-2050) and the accumulative anomaly(c:2021-2038). 
Earth Syst. Dynam. Discuss., doi:10.5194/esd-2017-13, 2017

Manuscript under review for journal Earth Syst. Dynam.

Discussion started: 22 February 2017

(c) Author(s) 2017. CC-BY 3.0 License.
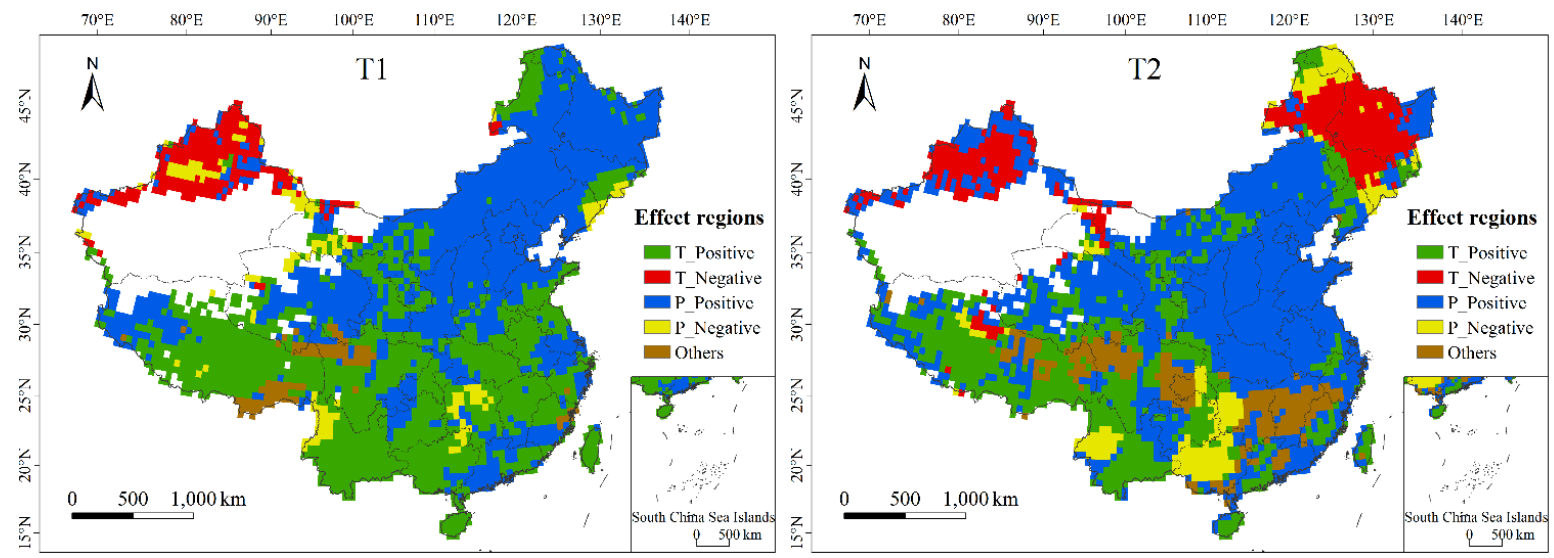

Figure 7: Effect regions of climatic factors in NPP rising (T1) and declining periods (T2) in the future.

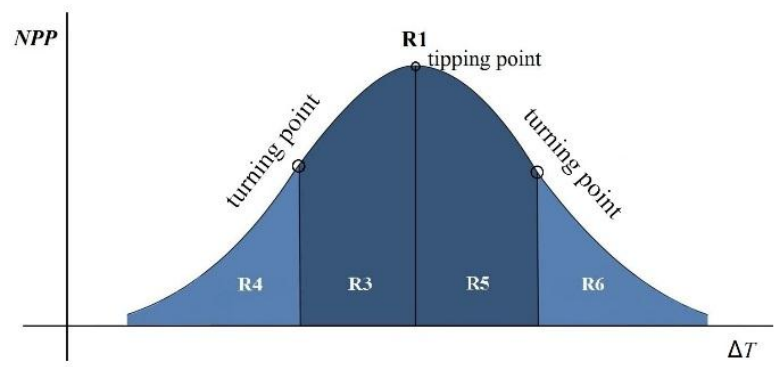

Figure 8: Theoretical process of vegetation response to temperature rising.

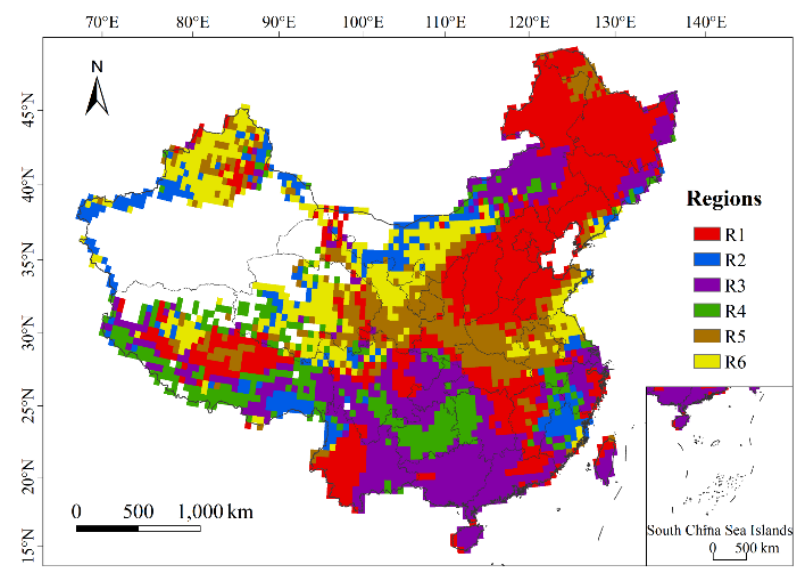

Figure 9: Regions for change in NPP trend from T1 to T2 period (R1: Uptrend to downtrend; R2: Downtrend to uptrend; R3: Uptrend slowed; R4: Uptrend accelerated; R5: Downtrend accelerated; R6: Downtrend slowed). 
Earth Syst. Dynam. Discuss., doi:10.5194/esd-2017-13, 2017

Manuscript under review for journal Earth Syst. Dynam.

Discussion started: 22 February 2017

(c) Author(s) 2017. CC-BY 3.0 License.

(c) (1)
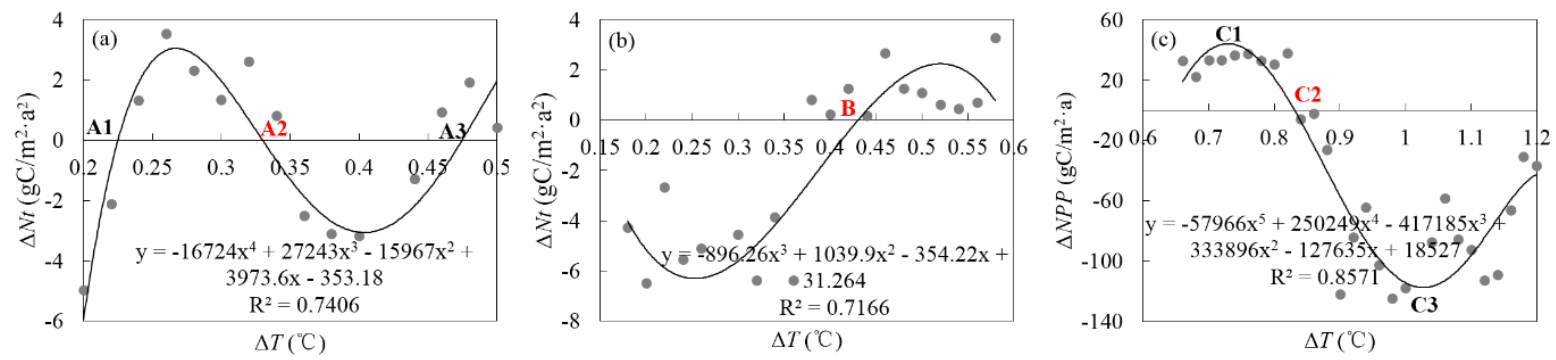

Figure 10: Fitting curve of vegetation change $(\triangle N P P / \Delta N t)$ and temperature change $(\Delta T)$ during T1 to T2 period (a:R4-R3 in the southwest, b:R5-R6 in the Loess Plateau, c:R3-R1-R5 in the northeast). 